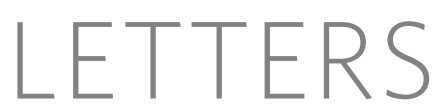

\title{
Stable isotope constraints on Holocene carbon cycle changes from an Antarctic ice core
}

\author{
Joachim Elsig ${ }^{1,2}$, Jochen Schmitt ${ }^{1,2,3}$, Daiana Leuenberger ${ }^{1,2}$, Robert Schneider ${ }^{1,2}$, Marc Eyer ${ }^{1,2}$, Markus Leuenberger ${ }^{1,2}$, \\ Fortunat Joos ${ }^{1,2}$, Hubertus Fischer ${ }^{1,2,3} \&$ Thomas F. Stocker ${ }^{1,2}$
}

Reconstructions of atmospheric $\mathrm{CO}_{2}$ concentrations based on Antarctic ice cores $^{1,2}$ reveal significant changes during the Holocene epoch, but the processes responsible for these changes in $\mathrm{CO}_{2}$ concentrations have not been unambiguously identified. Distinct characteristics in the carbon isotope signatures of the major carbon reservoirs (ocean, biosphere, sediments and atmosphere) constrain variations in the $\mathrm{CO}_{2}$ fluxes between those reservoirs. Here we present a highly resolved atmospheric $\delta^{13} \mathrm{C}$ record for the past 11,000 years from measurements on atmospheric $\mathrm{CO}_{2}$ trapped in an Antarctic ice core. From mass-balance inverse model calculations ${ }^{3,4}$ performed with a simplified carbon cycle model, we show that the decrease in atmospheric $\mathrm{CO}_{2}$ of about 5 parts per million by volume (p.p.m.v.). The increase in $\delta^{13} \mathrm{C}$ of about $0.25 \%$ during the early Holocene is most probably the result of a combination of carbon uptake of about $\mathbf{2 9 0}$ gigatonnes of carbon by the land biosphere and carbon release from the ocean in response to carbonate compensation of the terrestrial uptake during the termination of the last ice age. The 20 p.p.m.v. increase of atmospheric $\mathrm{CO}_{2}$ and the small decrease in $\delta^{13} \mathrm{C}$ of about $0.05 \%$ during the later Holocene can mostly be explained by contributions from carbonate compensation of earlier land-biosphere uptake and coral reef formation, with only a minor contribution from a small decrease of the land-biosphere carbon inventory.

The Holocene is the current interglacial period, starting about 11,000 years before present ( $11 \mathrm{kyr} \mathrm{BP}$, where present is defined as $\mathrm{AD} 1950$ ) following the Transition (here defined as 18-11 kyr BP) from the last glacial maximum. Variations in the atmospheric concentration of $\mathrm{CO}_{2}$ during the Holocene were significant but small compared to glacial-interglacial changes of typically 100 p.p.m.v. (refs 5, 6). Yet a decrease of about 5 p.p.m.v. from $11-7.5 \mathrm{kyr}$ BP could be observed, followed by an increase of about 20 p.p.m.v. to the pre-industrial level of about 280 p.p.m.v. (refs 1, 2, 7). Different explanations for these variations were discussed ${ }^{7,8}$, such as changes in the carbon inventories of vegetation, soils and peatlands ${ }^{9}$, in anthropogenic land use $\mathrm{e}^{10,11}$, in sea surface temperature $(\mathrm{SST})^{7,12}$, coral reef growth ${ }^{13,14}$ or carbonate compensation ${ }^{15}$. The latter is a multi-millennial equilibration process of the atmosphere-ocean-sediment system and the weathering cycle. Moreover, model simulations of atmospheric $\mathrm{CO}_{2}$ and $\delta^{13} \mathrm{C}$ during the Holocene have not provided an unambiguous quantitative explana$\operatorname{tion}^{7,8,16}$. The major stumbling block has been the scarcity of reconstructions of $\delta^{13} \mathrm{C}$ on atmospheric $\mathrm{CO}_{2}$ with sufficient accuracy and time resolution from the last glacial maximum to the Holocene $e^{7,17-20}$.

We performed carbon isotope measurements on air trapped in the EPICA (European Project for Ice Coring in Antarctica) Dome C $\left(75^{\circ} 06^{\prime} \mathrm{S}, 123^{\circ} 24^{\prime} \mathrm{E}\right)$ ice core using two completely independent extraction methods (mechanical cracking and sublimation, see Supplementary Information). Altogether, 199 single samples have been measured from 59 different depths in the interval of 110 to $410 \mathrm{~m}$. This interval corresponds to a gas age range of $11-0.35 \mathrm{kyr} \mathrm{BP}$ (ref. 21). The results are gravitationally corrected (see Supplementary Information) and are presented in Fig. 1. Of the 165 samples that were extracted with a mechanical cracker, a minimum of two were taken at each depth. For the remaining 34 samples we used a sublimation technique, and these are either single measurements or replications of three adjacent ice samples. The overall precision for a single measurement is $0.07 \%$ for both methods. The results of the two different methods agree very well within their uncertainties. The record clearly shows a continuous increase in the $\delta^{13} \mathrm{C}$ values during the first $5 \mathrm{kyr}$ of the Holocene, followed by only slightly decreasing values.

We focus on the evolution of the carbon isotopes on a timescale of a few thousand years. Therefore, we calculated a spline and its $1 \sigma$ uncertainty bands with a cut-off period of $5 \mathrm{kyr}$ (Fig. 2). In a Monte Carlo simulation, standard deviations smaller than $0.07 \%$ were

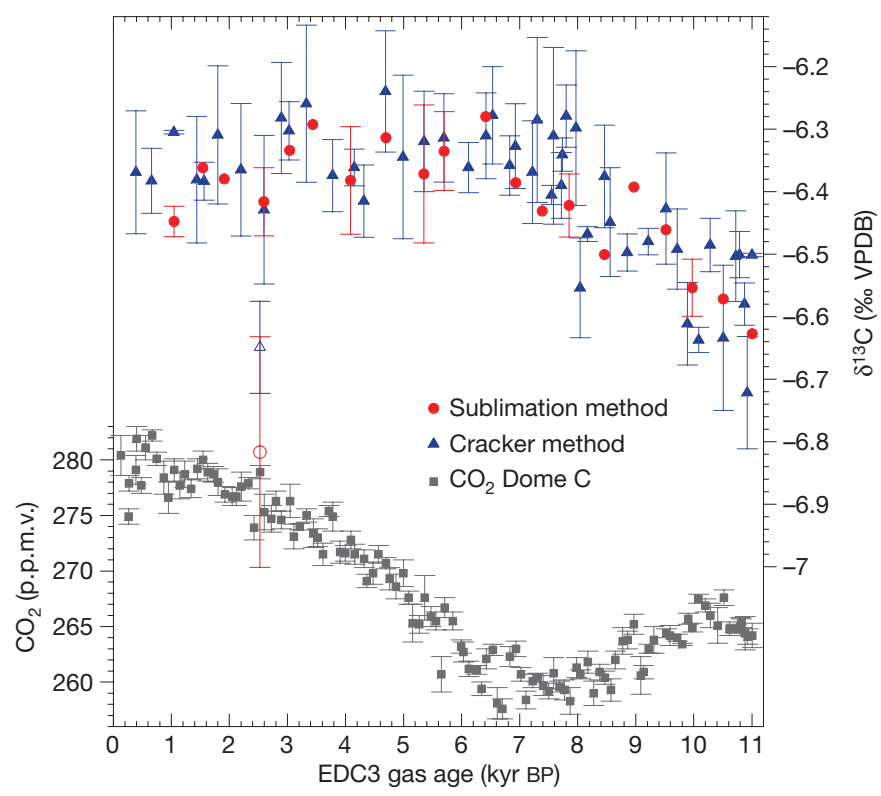

Figure $1 \mid \delta^{13} \mathrm{C}$ and $\mathrm{CO}_{2}{ }^{1,2}$ measured in air trapped in ice from Dome $\mathrm{C}_{\text {, }}$ Antarctica. Blue triangles indicate measurements performed with the cracker (mean of two to four samples); red circles indicate measurements with the sublimation method (single measurements or mean of three adjacent samples). Open symbols indicate outliers. The error bars represent the $t$-weighted $1 \sigma$ standard deviations of the mean. Grey squares represent $\mathrm{CO}_{2}$ data from Dome $\mathrm{C}$ (mean of six samples; error bars, $1 \sigma$ of the mean) ${ }^{21}$. EDC3, EPICA Dome C timescale version 3. 


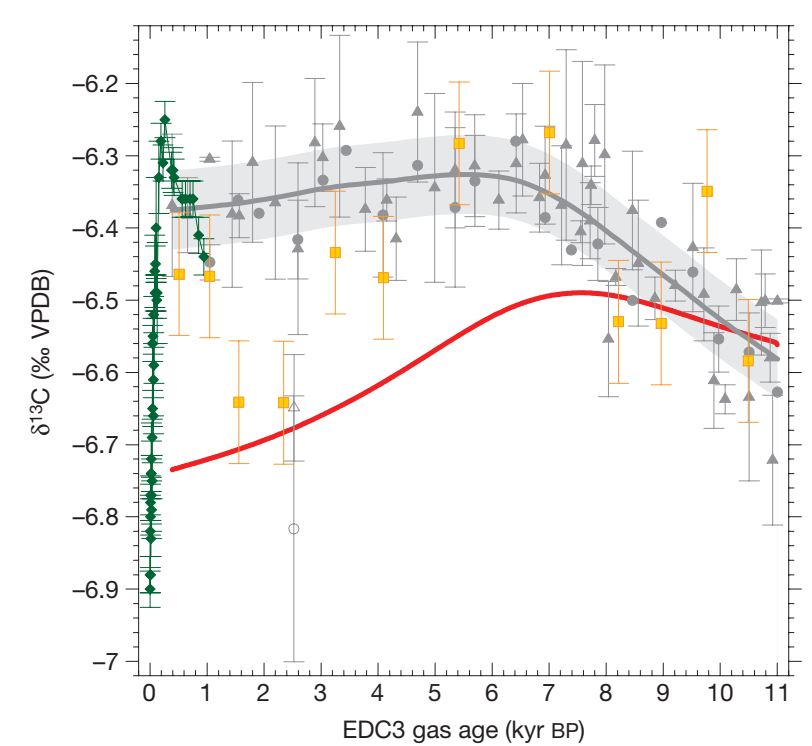

Figure $2 \mid \delta^{13} \mathrm{C}$ ice-core records measured on the Antarctic ice cores from Dome C, Taylor Dome ${ }^{7}$ and Law Dome ${ }^{22}$. Grey circles (sublimation method, this work) and grey triangles (cracker method, this work) refer to results from Dome C, yellow squares are data from Taylor Dome, and green diamonds are data from Law Dome. Grey open symbols indicate outliers. The error bars for Dome $\mathrm{C}$ measurements are the same as in Fig. 1. The error bars for the Taylor Dome and Law Dome data represent $1 \sigma$ of the mean. The grey spline through the Dome $\mathrm{C}$ data represents the mean of one hundred Monte Carlo simulations with a cut-off period of $5 \mathrm{kyr}$. The grey shaded area indicates $\pm 1 \sigma$ standard deviation of the spline. The red line is the result of a deconvolution of the atmospheric $\mathrm{CO}_{2}$ record, assuming the land-biosphere only scenario. VPDB, Vienna Pee-Dee Belemnite standard.

increased to $0.07 \%$; those higher than $0.07 \%$, however, were retained. Measurements at one depth interval (open symbols at 2.5 kyr BP in Fig. 1) led to exceptionally negative $\delta^{13} \mathrm{C}$ values significantly outside the $2 \sigma$ uncertainty range independently for both extraction methods. The reason for these outliers remains obscure, but the very large scatter in neighbouring samples despite the lowpass filtering effect of the bubble-enclosure process rules out an atmospheric origin of these outliers (see Supplementary Information). Accordingly, these two outliers are not included in the calculation of the spline.

Two main features of the carbon isotope record can be recognized: first, an almost linear increase from $-6.58 \%$ o to $-6.33 \%$ between 11 and $6 \mathrm{kyr} \mathrm{BP}$, and second, a small decrease of $0.05 \%$ in the later Holocene after 6 kyr BP. In Fig. 2 our data are compared with two published $\delta^{13} \mathrm{C}$ records, from the Taylor Dome ${ }^{7}$ and Law Dome ${ }^{22}$ ice cores. The relative timing of the Taylor Dome to Dome $\mathrm{C}$ gas age was adapted from Monnin et al. ${ }^{1}$, who matched the $\mathrm{CO}_{2}$ records of Dome $\mathrm{C}$ and Taylor Dome for the Holocene. The Taylor Dome data generally agree with our measurements except for three data points (out of 12) that have no overlap within the reported $1 \sigma$ uncertainties of our record. Our data are entirely consistent with the Law Dome record covering the last thousand years, providing a direct link to atmospheric measurements through the firn gas data from Law Dome $^{22}$.

We used our new, more precise and better resolved $\delta^{13} \mathrm{C}$ record to quantify carbon fluxes with different isotopic signatures and to test various hypotheses of Holocene $\mathrm{CO}_{2}$ variations. Previous mechanistic model studies ${ }^{8,14,16,23}$, ocean sediment analyses ${ }^{15}$, coral reef reconstructions ${ }^{24}$, and peatland data ${ }^{9,25}$ suggest that the Holocene $\mathrm{CO}_{2}$ variations were caused by land-biosphere uptake, carbonate compensation of earlier land-biosphere uptake, and the build-up of coral reefs made of calcium carbonate. In contrast, changes in $\mathrm{SST}^{12}$, ocean circulation and marine biological cycling, shifts in the proportion of $\mathrm{C}_{3}$ to $\mathrm{C}_{4}$ photosynthesis ${ }^{8}$, or changes in volcanic outgassing are assumed to be of minor importance for the Holocene $\mathrm{CO}_{2}$ and $\delta^{13} \mathrm{C}$ evolution. In addition, a strong release of $\mathrm{CO}_{2}$ over the past 7,000 years from anthropogenic land-use changes has previously been proposed ${ }^{10}$. The multitude and the spatio-temporal variability of the processes influencing atmospheric $\mathrm{CO}_{2}$ and $\delta^{13} \mathrm{C}$ prevent us from firmly attributing the measured changes to a single mechanism. However, the deconvolution of our new record by mass-balance inverse calculations $^{3,4,7}$ (see Supplementary Information) permits us to quantify atmosphere-ocean and atmosphere-land carbon fluxes for different hypotheses and to attribute the measured $\mathrm{CO}_{2}$ and $\delta^{13} \mathrm{C}$ changes to the most likely mechanisms.

Model calculations were performed with a cost-efficient impulse response representation of carbonate compensation and of the HighLatitude Exchange/Interior Diffusion-Advection ocean model coupled to a 4-box representation of vegetation and soils and a well-mixed atmosphere. The substitute model yields results for atmospheric $\mathrm{CO}_{2}$ and the redistribution of carbon and carbon isotopes between global reservoirs that are comparable to those of spatially resolved models. For instance, for the main scenario of land carbon uptake discussed below, the substitute model yields a late Holocene $\mathrm{CO}_{2}$ rise of 15 p.p.m.v. compared to 12 p.p.m.v. obtained with the Bern3D dynamic ocean-sediment model.

First, we assessed a land-biosphere-only scenario. Atmospheric $\mathrm{CO}_{2}$ variations were assumed to be driven entirely by changes in the land biosphere (using a fractionation for photosynthesis of $18.7 \%$; ref. 3 ) and the ocean-sediment system was assumed to react only passively. Solving the atmospheric $\mathrm{CO}_{2}$ budget for the unknown terrestrial flux yields a land-biosphere uptake of 75 gigatonnes of carbon (Gt C) from 11 to $7 \mathrm{kyr}$ BP and a release of $275 \mathrm{Gt} \mathrm{C}$ thereafter ${ }^{7}$. More importantly, the simulated evolution of atmospheric $\delta^{13} \mathrm{C}$ is not compatible with the $\delta^{13} \mathrm{C}$ measurements (Fig. 2). The release of isotopically depleted terrestrial carbon yields a modelled $\delta^{13} \mathrm{C}$ decrease of $0.25 \%$ after $8 \mathrm{kyr}$ BP, whereas our data show little change. Thus, suggestions that $\mathrm{CO}_{2}$ emissions from anthropogenic land-use change caused the late Holocene $\mathrm{CO}_{2}$ rise ${ }^{10}$ are quantitatively inconsistent with our $\delta^{13} \mathrm{C}$ record, as well as with other evidence ${ }^{8}$.

Other scenarios considering only one driving mechanism (changes in SST, the marine biological cycle, or the calcium carbonate cycle only), or the combination of marine biological changes and landbiosphere changes, are also in conflict with the measured co-evolution of $\mathrm{CO}_{2}$ and $\delta^{13} \mathrm{C}$ and with other proxy evidence. For example, an unrealistically large global average SST increase of $2.5^{\circ} \mathrm{C}$ is required to explain the $\delta^{13} \mathrm{C}$ increase of $0.25 \%$ from 11 to $6 \mathrm{kyr}$ BP by SST changes only. A combination of SST and land-biosphere changes (tested by deconvolving both atmospheric records simultaneously) implies a global average SST increase of about $1.5^{\circ} \mathrm{C}$, which is in conflict with alkenone-based SST reconstructions $\left(0.2 \pm 0.2^{\circ} \mathrm{C}\right.$ since $8 \mathrm{kyr} \mathrm{BP}$, ref. 26) and model calculations ${ }^{12,27}$. This is different from earlier findings by Indermühle et al. ${ }^{7}$, who applied the same modelling approach but had to rely on very few $\delta^{13} \mathrm{C}$ values. They suggested that changes in the land biosphere with a modest temperature increase, possibly in combination with changes in the marine-carbonate cycle, are responsible for the Holocene $\mathrm{CO}_{2}$ evolution. Our improved $\delta^{13} \mathrm{C}$ record permits us now to exclude this land-biosphere-global SST scenario.

Finally, we turn to the land-biosphere-marine-carbonate scenario, which assumes that atmospheric variations are caused by changes in the land biosphere in combination with carbonate compensation and coral reef growth. Both marine-carbonate processes are associated with small isotopic fractionations and cannot be distinguished by $\delta^{13} \mathrm{C}$ data, nor can they significantly influence atmospheric $\delta^{13} \mathrm{C}$. Solving the two atmospheric budgets for $\mathrm{CO}_{2}$ and $\delta^{13} \mathrm{C}$ yields a land-biosphere uptake of $(290 \pm 36) \mathrm{Gt} \mathrm{C}$ (mean and $\pm 1 \sigma$ confidence interval from a Monte Carlo analysis) during the period 11-5 kyr BP and a release of $(36 \pm 37) \mathrm{Gt} C$ thereafter (Fig. 3a). We note that the substitute model represents global mean fluxes and is not able to capture the influence of spatial variations in carbon and isotopic 


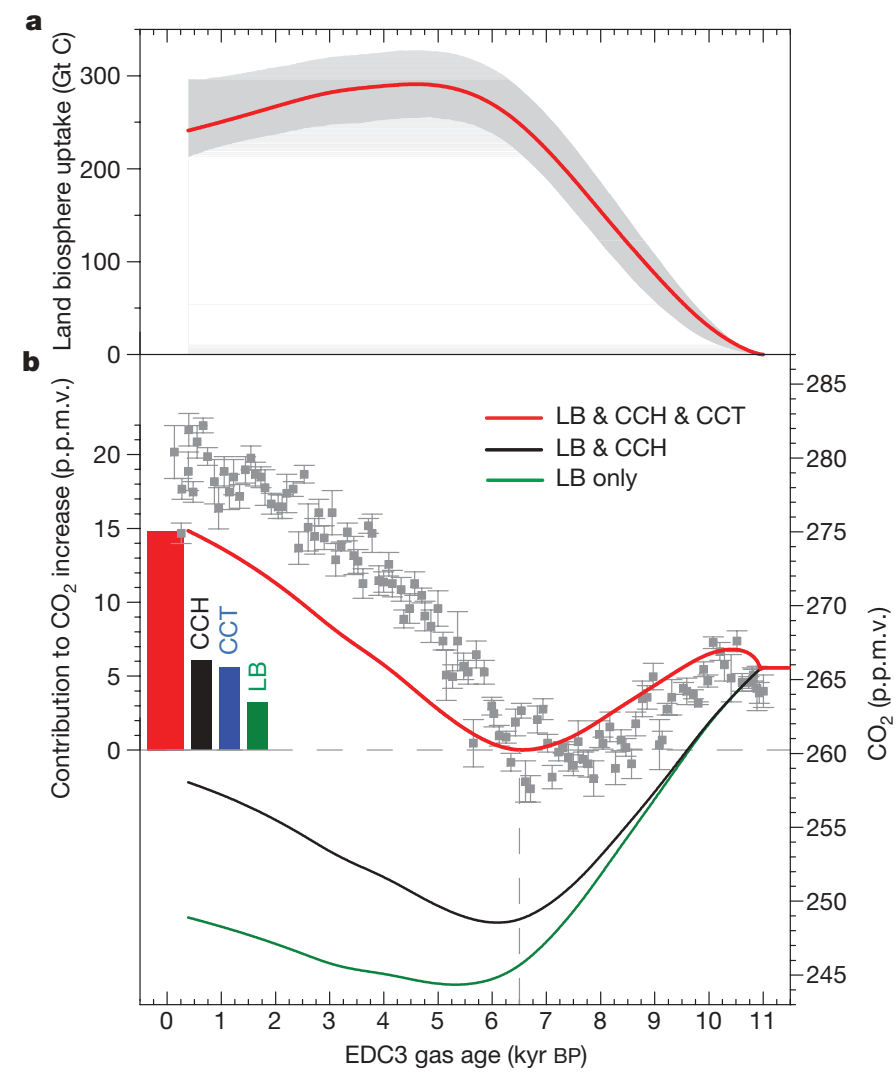

Figure 3 Attribution of simulated $\mathrm{CO}_{2}$ to different processes.

a, Cumulative land-biosphere uptake for the land-biosphere-marinecarbonate scenario from deconvolving the atmospheric $\mathrm{CO}_{2}($ refs 1,2$)$ and $\delta^{13} \mathrm{C}$ records. The shaded area indicates the $1 \sigma$ confidence interval of a Monte Carlo analysis ${ }^{4}$, taking into account the uncertainty of the ice-core data. $\mathbf{b}$, Atmospheric $\mathrm{CO}_{2}$ is simulated by prescribing the land-biosphere changes shown in a. Grey squares represent $\mathrm{CO}_{2}$ data from Dome C (mean of six samples; error bars, $1 \sigma$ of the mean). Green line, land biosphere (LB) only; black line, LB and carbonate compensation during the Holocene $(\mathrm{CCH})$; red line, $\mathrm{LB}$ plus $\mathrm{CCH}$ plus $700 \mathrm{Gt} \mathrm{C}$ land biosphere uptake during the transition which causes carbonate compensation (CCT). The bar chart indicates the modelled contributions to the $\mathrm{CO}_{2}$ rise from 6.5-0 kyr вр by individual processes $\mathrm{LB}, \mathrm{CCT}$ and $\mathrm{CCH}$, and the total (red bar), assuming the land-biosphere-marine-carbonate scenario. The remaining difference between the simulated and measured $\mathrm{CO}_{2}$ increase may be attributed to coral reef growth and other mechanisms.

exchange. Potential contributions from other processes such as volcanism, SST changes or changes in the marine biological cycle are neglected in the land-biosphere-marine-carbonate scenario.

Are these fluxes inferred from our mass-balance calculation realistic and in agreement with proxy data, model results and process understanding? The early Holocene land-biosphere uptake of $290 \mathrm{Gt}$ C is compatible with an early Holocene uptake of $110 \mathrm{Gt} \mathrm{C}$ simulated by the Lund-Potsdam-Jena Dynamic Vegetation model on non-peatland land in response to reconstructed ice-sheet retreat, climate and $\mathrm{CO}_{2}$ variations 8 . This requires an early Holocene increase in peat carbon by $180 \mathrm{GtC}$. Current inventories of peat carbon range from 270 to $455 \mathrm{Gt} \mathrm{C}$ (ref. 9). Radiocarbon dating suggests initiation of peat accumulation already occurring during the Transition with a major expansion of peat area in the early Holocene ${ }^{9}$, but also some peat accumulation in recent millennia ${ }^{28}$. A land-biosphere release of $\sim 40 \mathrm{Gt} \mathrm{C}$ in the later Holocene may be explained by a model-estimated release of $30 \mathrm{GtC}$ due to the desertification of the Sahara ${ }^{7}$, plus a modelled release of around $50 \mathrm{Gt} C$ from pre-1,500 AD anthropogenic land-use change ${ }^{11}$, plus an implied peat carbon uptake of $\sim 40 \mathrm{GtC}$. The implied Holocene peat carbon uptake of $220 \mathrm{Gt} C$ is somewhat lower than the published range for the current carbon inventory in peat carbon'. This might be explained by peat carbon uptake during the
Transition. Alternatively, natural carbon release from land might have been larger than $30 \mathrm{Gt} C$ (ref. 23), also implying a higher uptake by peat.

In a next step, the atmosphere-ocean component of our carbon cycle model was used in forward simulations to test mechanistic explanations of inferred ocean-driven $\mathrm{CO}_{2}$ changes. First, we prescribe the atmosphere-land fluxes from the land-biosphere-carbonatecompensation scenario to separate the contribution from Holocene land-biosphere changes. The atmospheric $\delta^{13} \mathrm{C}$ record is matched by design. The Holocene land-biosphere changes result in an initial decrease in atmospheric $\mathrm{CO}_{2}$ of about 17 p.p.m.v., which is much larger than that measured in ice cores, and an increase of $\sim 9$ p.p.m.v. after $6.5 \mathrm{kyr}$ BP (Fig. 3b). The increase is attributed to carbonate compensation of the early Holocene land-biosphere uptake ( $\sim 6$ p.p.m.v.) and to the (prescribed) land-biosphere release of $50 \mathrm{Gt} \mathrm{C}$ ( $\sim 3$ p.p.m.v.). Second, we consider that carbonate compensation caused by the landbiosphere uptake during the Transition also contributed to the Holocene $\mathrm{CO}_{2}$ rise. Land-biosphere carbon inventory changes over the glacial-interglacial period have been estimated to be from $500 \mathrm{Gt} C$ to more than $1,000 \mathrm{Gt} \mathrm{C}$ (refs 29, 30). In our simulations we have prescribed a linear increase of the land-biosphere inventory by $700 \mathrm{Gt} \mathrm{C}$ during the Transition. This yields a simulated early Holocene $\mathrm{CO}_{2}$ decrease comparable to the ice-core data and a late Holocene rise of $\sim 15$ p.p.m.v., somewhat smaller than reconstructed (see Supplementary Information for additional sensitivity simulations).

The remaining $\sim 5$ p.p.m.v. in atmospheric $\mathrm{CO}_{2}$ can plausibly be explained by coral reef growth. Coral reef formation changes the carbonate ion balance in sea water and increases atmospheric $\mathrm{CO}_{2}$ (ref. 13). Vecsei and Berger ${ }^{24}$ reconstructed a calcium carbonate accumulation by reefs of $260 \mathrm{Gt} C$ during the past $8 \mathrm{kyr}$. This implies a $\mathrm{CO}_{2}$ rise by another $\sim 8$ p.p.m.v. (ref. 14 ), compatible with the ice-core data and model results. However, our modelling results and the $\delta^{13} \mathrm{C}$ record do not quantitatively support the suggestion that coral reef growth caused a much larger $\mathrm{CO}_{2}$ rise of 20 to 40 p.p.m.v. (ref. 14) during the late Holocene.

High-resolution and high-precision ice-core data on atmospheric $\delta^{13} \mathrm{C}$ can significantly constrain the possible pathways of the carbon cycle evolution in the past. Using carbon cycle modelling, our new $\delta^{13} \mathrm{C}$ data show that the evolution of atmospheric $\mathrm{CO}_{2}$ over the past $11 \mathrm{kyr}$ is dominated by an early Holocene increase in land biosphere and changes in the marine-carbonate cycle. Our $\delta^{13} \mathrm{C}$ record renders untenable suggestions that $\mathrm{CO}_{2}$ emissions from anthropogenic landuse changes caused the later Holocene $\mathrm{CO}_{2}$ rise $^{10}$ and prevented a new ice age. The attribution of the $\mathrm{CO}_{2}$ changes to specific changes in the marine-carbonate cycle (including coral reef growth, carbonate compensation of land-biosphere carbon uptake, sediment-ocean interactions related to the reorganization of the marine carbon cycle during the glacial-interglacial transition, or changes in weathering fluxes) is challenging. Further progress requires an extension of our atmospheric $\delta^{13} \mathrm{C}$ record into the glacial period as well as process studies with three-dimensional physical-biogeochemical climate models.

\section{METHODS SUMMARY}

For the cracker method we use a mechanical extraction device (steel needle cracker), which crushes the ice sample (6g) under vacuum to release the enclosed gases in the ice. In the sublimation method the gases are extracted from the ice sample ( $30 \mathrm{~g}$ ) using sublimation at $-25^{\circ} \mathrm{C}$ in a glass vessel. In both methods the released air is dried in a water trap and the amount of air is measured with a pressure gauge to calculate the $\mathrm{CO}_{2}$ concentration. $\mathrm{CO}_{2}$ and $\mathrm{N}_{2} \mathrm{O}$ are separated from the major air components at $-196{ }^{\circ} \mathrm{C}$ using liquid nitrogen with subsequent concentration by means of a cryofocus capillary to ensure complete gas chromatographic separation. After having passed through a chromatographic column to separate isobaric components $\left(\mathrm{N}_{2} \mathrm{O}\right.$ and organic components from drilling fluid) the purified $\mathrm{CO}_{2}$ sample is injected via an open-split tube into the isotope ratio mass spectrometer (a Delta Plus XL for the cracker method and a MAT 253 for the sublimation method, both ThermoFisher). Both extraction systems are equipped with inlet devices which allow the processing of 
calibrated reference gases in the same way as the ice samples. This allows us to check the system and reference the results from the ice samples to an international standard.

\section{Received 4 May; accepted 28 July 2009.}

1. Monnin, E. et al. Atmospheric $\mathrm{CO}_{2}$ concentrations over the last glacial termination. Science 291, 112-114 (2001).

2. Flückiger, J. et al. High-resolution Holocene $\mathrm{N}_{2} \mathrm{O}$ ice core record and its relationship with $\mathrm{CH}_{4}$ and $\mathrm{CO}_{2}$. Glob. Biogeochem. Cycles 16, 1010, doi:10.1029/ 2001GB001417 (2002).

3. Joos, F. \& Bruno, M. Long-term variability of the terrestrial and oceanic carbon sinks and the budgets of the carbon isotopes ${ }^{13} \mathrm{C}$ and ${ }^{14} \mathrm{C}$. Glob. Biogeochem. Cycles 12, 277-295 (1998).

4. Bruno, M. \& Joos, F. Terrestrial carbon storage during the past 200 years: a Monte Carlo analysis of $\mathrm{CO}_{2}$ data from ice core and atmospheric measurements. Glob. Biogeochem. Cycles 11, 111-124 (1997).

5. Lüthi, D. et al. High-resolution carbon dioxide concentration record 650,000-800,000 years before present. Nature 453, 379-382 (2008).

6. Sigman, D. M. \& Boyle, E. A. Glacial/interglacial variations in atmospheric carbon dioxide. Nature 407, 859-869 (2000).

7. Indermühle, A. et al. Holocene carbon-cycle dynamics based on $\mathrm{CO}_{2}$ trapped in ice at Taylor Dome, Antarctica. Nature 398, 121-126 (1999).

8. Joos, F., Gerber, S., Prentice, I. C., Otto-Bliesner, B. L. \& Valdes, P. J. Transient simulations of Holocene atmospheric carbon dioxide and terrestrial carbon since the Last Glacial Maximum. Glob. Biogeochem. Cycles 18, GB2002, doi:10.1029/ 2003GB002156 (2004).

9. MacDonald, G. M. et al. Rapid early development of circumarctic peatlands and atmospheric $\mathrm{CH}_{4}$ and $\mathrm{CO}_{2}$ variations. Science 314, 285-288 (2006).

10. Ruddiman, W. F. The anthropogenic greenhouse era began thousands of years ago. Clim. Change 61, 261-293 (2003).

11. Strassmann, K. M., Joos, F. \& Fischer, G. Simulating effects of land use changes on carbon fluxes: past contributions to atmospheric $\mathrm{CO}_{2}$ increases and future commitments due to losses of terrestrial sink capacity. Tellus B60,583-603 (2008).

12. Brovkin, V., Kim, J. H., Hofmann, M. \& Schneider, R. A lowering effect of reconstructed Holocene changes in sea surface temperatures on the atmospheric $\mathrm{CO}_{2}$ concentration. Glob. Biogeochem. Cycles 22, GB1016, doi:10.1029/ 2006GB002885 (2008).

13. Berger, W. H. Increase of carbon dioxide in the atmosphere during deglaciationthe coral-reef hypothesis. Naturwissenschaften 69, 87-88 (1982).

14. Ridgwell, A. J., Watson, A. J., Maslin, M. A. \& Kaplan, J. O. Implications of coral reef buildup for the controls on atmospheric $\mathrm{CO}_{2}$ since the Last Glacial Maximum. Paleoceanography 18, 1083-1092 (2003).

15. Broecker, W. S., Lynch-Stieglitz, J., Clark, E., Hajdas, I. \& Bonani, G. What caused the atmosphere's $\mathrm{CO}_{2}$ content to rise during the last 8000 years? Geochem. Geophys. Geosyst. 2, 1062, doi:10.1029/2001GC000177 (2001).

16. Brovkin, V. et al. Carbon cycle, vegetation, and climate dynamics in the Holocene: experiments with the CLIMBER-2 model. Glob. Biogeochem. Cycles 16, doi:10.1029/2001GB001662 (2002).

17. Smith, H. J., Fischer, H., Wahlen, M., Mastroianni, D. \& Deck, B. Dual modes of the carbon cycle since the Last Glacial Maximum. Nature 400, 248-250 (1999).

18. Leuenberger, M., Siegenthaler, U. \& Langway, C. C. Carbon isotope composition of atmospheric $\mathrm{CO}_{2}$ during the last ice-age from an Antarctic ice core. Nature 357, 488-490 (1992).
19. Eyer, M. Highly Resolved $\delta^{13} \mathrm{C}$ Measurements on $\mathrm{CO}_{2}$ in Air from Antarctic Ice Cores. 1-113, PhD thesis, Univ. Bern (2004).

20. Lourantou, A. Contraindre l'Augmentation en Dioxyde de Carbone $\left(\mathrm{CO}_{2}\right)$ lors des Déglaciations Basés sur son Rapport Isotopique Stable du Carbone $\left(\delta^{13} \mathrm{CO}_{2}\right)$. PhD thesis, Univ. Joseph Fourier (2008).

21. Loulergue, L. et al. New constraints on the gas age-ice age difference along the EPICA ice cores, 0-50 kyr. Clim. Past 3, 527-540 (2007).

22. Francey, R. J. et al. A 1000 -year high precision record of $\delta^{13} \mathrm{C}$ in atmospheric $\mathrm{CO}_{2}$. Tellus B 51, 170-193 (1999).

23. Schurgers, G. et al. Dynamics of the terrestrial biosphere, climate and atmospheric $\mathrm{CO}_{2}$ concentration during interglacials: a comparison between Eemian and Holocene. Clim. Past 2, 205-220 (2006).

24. Vecsei, A. \& Berger, W. H. Increase of atmospheric $\mathrm{CO}_{2}$ during deglaciation: constraints on the coral reef hypothesis from patterns of deposition. Glob. Biogeochem. Cycles 18, GB1035, doi:10.1029/2003GB002147 (2004).

25. Smith, L. C. et al. Siberian peatlands a net carbon sink and global methane source since the early Holocene. Science 303, 353-356 (2004).

26. Kim, J. H. et al. North Pacific and North Atlantic sea-surface temperature variability during the holocene. Quat. Sci. Rev. 23, 2141-2154 (2004).

27. Wang, Y., Mysak, L. A. \& Roulet, N. T. Holocene climate and carbon cycle dynamics: experiments with the "green" McGill Paleoclimate Model. Glob. Biogeochem. Cycles 19, GB3022, doi:10.1029/2005GB002484 (2005).

28. Beilman, D. W., MacDonald, G. M., Smith, L. C. \& Reimer, P. J. Carbon accumulation in peatlands of West Siberia over the last 2000 years. Glob. Biogeochem. Cycles 23, GB1012, doi:10.1029/2007GB003112 (2009).

29. Duplessy, J. C. et al. Deepwater source variations during the last climatic cycle and their impact on the global deepwater circulation. Paleoceanography 3, 343-360 (1988).

30. Crowley, T. J. Ice-age terrestrial carbon changes revisited. Glob. Biogeochem. Cycles 9, 377-389 (1995).

Supplementary Information is linked to the online version of the paper at www.nature.com/nature.

Acknowledgements This work is a contribution to the European Project for Ice Coring in Antarctica (EPICA), a joint European Science Foundation/European Commission scientific programme, funded by the EU (EPICA-MIS) and by national contributions from Belgium, Denmark, France, Germany, Italy, the Netherlands, Norway, Sweden, Switzerland and the United Kingdom. The main logistic support was provided by IPEV and PNRA (at Dome C) and AWI (at Dronning Maud Land). We thank A. Landais, D. Rodriguez, E. Capron and G. Dreyfus for the contribution of $\delta^{15} \mathrm{~N}$ data as well as P. Nyfeler and K. Grossenbacher for their technical support, T. Tschumi for sharing his Bern3D results, and J. Chappellaz for comments. We acknowledge financial support by the Swiss NSF, the DFG priority programme INTERDYNAMIK and the German climate programme DEKLIM. This is EPICA publication no. 227.

Author Contributions J.E., J.S., D.L., R.S. and M.E. performed the measurements. F.J. performed modelling and interpretation. M.L., H.F. and T.F.S designed the research. All authors participated in discussions on method development, interpretation and presentation of results.

Author Information Reprints and permissions information is available at www.nature.com/reprints. Correspondence and requests for materials should be addressed to T.F.S. (stocker@climate.unibe.ch). 